\title{
Abrindo caminho para o futuro: redes de apoio social e resiliência em autobiografias de jovens socioeconomicamente vulneráveis
}

\author{
Idilva Maria Pires Germano \\ Veriana de Fátima Rodrigues Colaço \\ Universidade Federal do Ceará
}

\begin{abstract}
Resumo
Este trabalho discute processos de resiliência e redes de apoio social a partir de entrevistas narrativas realizadas com jovens socioeconomicamente desfavorecidos de escolas públicas de Fortaleza. O objetivo do estudo foi analisar como contavam suas histórias de vida, especialmente como enfrentavam adversidades em busca de recursos promotores de saúde e bem-estar. Os relatos foram analisados temática e narrativamente a fim de compreender como os jovens recrutam recursos pessoais, familiares, comunitários e culturais disponíveis e como esses recursos e as formas de manejo atuam de modo protetivo. Considerando que a resiliência também implica a disponibilidade dos recursos buscados pelo jovem, atenção especial foi dada à capacidade de suas comunidades em fornecê-los apropriadamente. Um resultado significativo é sua percepção do poder público como ineficaz ou ausente. Frente ao declínio da esfera pública, o jovem tende a refugiar-se na família e em seus próprios recursos pessoais para enfrentar o futuro.
\end{abstract}

Palavras-chave: redes de apoio social; resiliência; juventude; vulnerabilidade social.

\begin{abstract}
Paving the way to the future: social support networks and resilience in autobiographies of socioeconomically vulnerable youth. This work discusses resilience processes and social support networks among youth based on narrative interviews with socioeconomically disadvantaged students from public schools in Fortaleza (Brazil). The aim of the study was to analyze how they told their life stories, particularly how they dealt with adversities, navigating their way to health-sustaining resources and well-being. Thematic and narrative analysis were applied to understand the way youth achieve personal, family, community and cultural resources and how these resources and strategies have a protective effect. Considering that resilience also refers to the availability of the resources sought special attention was directed to their communities' capacity to properly provide them. A meaningful result is their perception of public politics and services as ineffective or absent. Facing the decline of the public sphere, youth tend to take refuge in the family and in their own personal resources as means to stand up to their future.
\end{abstract}

Keywords: social support networks; resilience; youth; social vulnerability.

Rede de apoio e resiliência: explorando as tensões negociadas por jovens em desvantagem

Muito tem se falado sobre o papel da rede de apoio social na construção subjetiva, organização identitária e desenvolvimento psicossocial, especialmente em se tratando de populações menos favorecidas economicamente ou consideradas em situação de vulnerabilidade social. Diferentes enfoques podem ser dados a essa noção, porém, o que os unifica é a ideia de rede de apoio como uma trama de relações sociais articuladas de forma densa na qual se movem as pessoas e coletividades em seus ambientes físicos e sociais. Movimentar-se nessa trama obtendo suporte para uma vida saudável ao longo do desenvolvimento pessoal e social define o sentido positivo de rede de apoio.

Conceitualmente entendemos por rede de apoio um complexo sistema de ações, relações e intervenções, que ocorre tanto num plano microssocial, o qual comporta a família, amigos, grupos sociais mais próximos, quanto num plano macrossocial, envolvendo as políticas públicas em geral (saúde, educação, cultura, esporte, lazer, habitação e trabalho), que são ou deveriam ser efetivadas por instituições governamentais e não governamentais, órgãos especiais e também por pessoas nas interações do convívio cotidiano.

Alguns estudos recentes (Amparo, Galvão, Alves, Brasil, \& Koller, 2008; Andrade \& Vaitsman, 2002; Costa, 2009; Marques \& Bichir, 2011; Siqueira, Betts, \& Dell Aglio, 2006) têm abordado o alcance e os limites das redes de apoio no contexto brasileiro, questionando a sua disponibilidade e o seu acesso por crianças, jovens e suas famílias e comunidades, nos campos da saúde, educação, trabalho e segurança. Temas como comportamentos de risco (por exemplo, consumo de drogas e sexo não seguro), ato 
infracional e conflito com a lei e institucionalização de crianças e jovens recebem particular atenção, mobilizando pesquisadores a produzir subsídios para o aperfeiçoamento de políticas e ações nesses quesitos. Levantamentos e diagnósticos sobre fatores de risco e redes de apoio social nos variados contextos urbanos no país são acompanhados por esforços de teorização, que levam estudiosos a refletir sobre os processos interacionais no curso da vida e sua relação com o desenvolvimento saudável, mesmo em circunstâncias adversas. Nesse sentido, os estudos sobre processos de resiliência ganham relevo, assinalando as complexas conexões entre os indivíduos e seus ambientes materiais e sociais que condicionam o modo como negociam variados recursos em direção à saúde e ao bem-estar (Dell'Aglio, Koller, \& Yunes, 2006; Libório, 2009; Yunes, 2003). Tais estudos, orientados por princípios da Psicologia Positiva, concentram-se nos potenciais e aspectos saudáveis das pessoas (em seus contextos relacionais), que as capacitam a enfrentar, de forma bem sucedida, obstáculos e adversidades em seu desenvolvimento. O que se revela nesses trabalhos é o poder das relações pessoais e sociais como base para a superação de dificuldades cotidianas e situações excepcionais que ameaçam ou prejudicam o bem-estar e a qualidade de vida, com resultados danosos em termos de saúde física e mental. Assim, a possibilidade de se contar com uma rede de suporte social que abarque o círculo de amigos, a família, a comunidade e o ambiente cultural faz toda a diferença quando se trata de superar condições de risco e vulnerabilidade social.

Neste artigo, discutiremos o manejo de recursos pessoais, familiares, comunitários e culturais por jovens no enfrentamento de situações de vulnerabilidade social, obtidos numa pesquisa sobre processos biográficos e projetos de vida juvenis, realizada em Fortaleza. A pesquisa, de orientação qualitativa, faz parte de uma investigação quantitativa mais abrangente que examinou fatores de risco social e redes de proteção, mediante questionário, numa amostra de 1.140 alunos de 14 a 24 anos, de ambos os sexos, da rede pública de ensino dessa capital.

O subprojeto qualitativo estava interessado em abordar as questões de risco, vulnerabilidade e proteção social, sob uma perspectiva narrativo-biográfica, como forma de compreender essas temáticas, enfatizando aspectos (inter)subjetivos e processuais.

Uma das linhas de análise buscou compreender como os jovens recrutam os variados recursos disponíveis para o enfrentamento de riscos e adversidades significativas em casa, na escola, no bairro e no trabalho; e como esses recursos e as formas de manejo atuam de modo protetivo, garantindo bemestar ao jovem. Nesse sentido, esse estudo discute os processos de resiliência que se revelam nas narrativas autobiográficas dos jovens entrevistados, apoiando-se particularmente nos estudos de orientação construcionista e transcultural de Michael Ungar e colaboradores (Libório \& Ungar, 2010; Ungar, 2003; 2004; Ungar, Brown, Liebenberg, Cheung, \& Levine, 2008) que têm discutido o conceito em termos de "tensões" entre indivíduos, famílias, comunidades e culturas. Essas tensões - a saber, acesso a recursos materiais, desenvolvimento de uma identidade pessoal desejável, acesso a relacionamentos interpessoais que fornecem apoio, experiências de coesão social, aderência cultural, poder e controle pessoal, justiça social - devem ser negociadas no curso da vida e com base em contextos socioculturais situados.

Como explicam os autores acima, a tensão do acesso a recursos materiais envolve a possibilidade de o jovem obter suporte financeiro para suas necessidades básicas, no plano alimentar, de saúde, de educação e de trabalho. A tensão da identidade pessoal refere-se à possibilidade de desenvolver um senso valorizado de individualidade em relação com os outros e nos múltiplos espaços de interação. A tensão dos relacionamentos implica a possibilidade de estabelecer relações significativas com pares, amigos, familiares, professores e outros que podem fornecer afeto e suporte emocional. A tensão da coesão social envolve a possibilidade de desenvolver o senso de responsabilidade e compromisso com sua família e comunidade mais ampla. A aderência cultural trata da capacidade de aceitar ou desafiar as normas culturais, crenças e valores partilhados na sua comunidade local e/ou em âmbito global. A tensão do poder e controle pessoais implica a condição de tomar decisões e de agir (agency), e o controle de concretizá-las envolve a autoconfiança e a capacidade de o jovem cuidar de si e de outros e imprimir mudanças no seu ambiente, a fim de alcançar recursos que promovam seu bem-estar. Por fim, a tensão da justiça social refere-se à possibilidade de o jovem reivindicar e assegurar seus direitos individual e coletivamente, contra preconceitos e formas de opressão sociopolítica, encontrando um papel significativo que lhe traz aceitação e igualdade social.

Como resumem Ungar, Brown, Liebenberg, Cheung e Levine (2008), a resiliência implica três aspectos: primeiramente, a competência dos indivíduos de navegar em direção aos recursos promotores de bem-estar; segundo, a capacidade de suas comunidades (as ecologias físicas e sociais) de fornecer esses recursos e, terceiro, a capacidade de indivíduos, suas famílias e comunidades de negociar caminhos culturalmente significativos para os recursos a serem partilhados.

As entrevistas narrativas foram analisadas com base nas noções de resiliência como "navegação em direção a" recursos promotores de saúde e bem-estar e como "negociação de tensões" que conferem maior relativismo e dinamismo ao conceito. Neste trabalho, tecemos algumas considerações baseadas nas entrevistas narrativas acerca do modo como esses jovens abrem caminho em direção ao que definem e imaginam como um futuro saudável e feliz (em seus próprios termos), vencendo os desafios que seus ambientes lhes impõem. Certas configurações entre o que o jovem demanda de sua rede de apoio e o que lhe é oferecido nos variados ambientes em que circula, podem ter efeitos danosos ou benéficos. As entrevistas narrativas permitem investigar o que o jovem vivencia em termos do apoio buscado, oferecido e negado na rede, uma vez que seu formato estimula o jovem a organizar sua história (mesmo que provisoriamente) e avaliar diversos episódios e situações como benéficos ou prejudiciais para si e para outros. Para pesquisadores de processos de resiliência, permitem especialmente acompanhar a emergência e o desenvolvimento de processos de sofrimento nas biografias juvenis, bem como as formas de enfrentamento, superação e mudança pessoal.

A relação entre rede de apoio e processo de resiliência, em se tratando de adolescentes e jovens no Brasil, deve ser compreendida à luz da Doutrina da Proteção Integral que 
fundamenta a construção do Estatuto da Criança e do Adolescente - ECA (1990). São basilares os Art. 4: "É dever da família, da comunidade, da sociedade em geral e do poder público assegurar, com absoluta prioridade, a efetivação dos direitos referentes à vida, à saúde, à alimentação, à educação, ao respeito, à liberdade e à convivência familiar e comunitária" e Art. 86: "A política de atendimento dos direitos da criança e do adolescente far-se-á através de um conjunto articulado de ações governamentais e não governamentais da União, dos Estados, do Distrito Federal". Isto é, sendo a criança e o adolescente prioridades em todos os setores das políticas públicas para que se lhes assegurem as condições básicas ao seu pleno desenvolvimento, esse conjunto articulado de ações está previsto pelo Sistema de Garantia de Direitos que compõe a rede de apoio social e pessoal para esse segmento populacional. Mas, em que medida esse sistema é efetivado? Qual a implementação e eficácia das políticas públicas destinadas às crianças e adolescentes? Qual a real intersetorialidade das políticas para serem reconhecidas em rede?

$\mathrm{Na}$ área da infância e adolescência, a partir do ECA, foram criados órgãos especificamente voltados para a garantia de seus direitos, como é o caso dos Conselhos Estadual e Municipal de Direitos, que se destinam a propor políticas que assegurem a efetivação e o cumprimento do ECA no âmbito do estado e do município, de acordo com a sua competência; dos Conselhos Tutelares, órgãos fiscalizadores, os quais devem intervir quando os direitos são violados; da Delegacia da Criança e do Adolescente - DCA e da Delegacia de Combate à Exploração da Criança e do Adolescente - DECECA, encarregadas de investigar e atuar em situações de violência contra criança e adolescente, além de casos de atos infracionais supostamente realizados por eles. E no nível judicial, as Varas Especializadas da Infância e da Juventude dos municípios.

Esse complexo aparato institucional tem o propósito de desenvolver ações complementares entre si, e de modo articulado, às políticas e aos equipamentos para sua efetivação, tais como a rede pública de ensino municipal, estadual e federal, o sistema público de saúde, os recursos de promoção de cultura e lazer, além daqueles que estão voltados à execução da Política Nacional de Assistência Social - PNAS, como é o caso dos Centros de Referência Especializado de Assistência Social - CREAS e do Sistema Nacional de Atendimento Socioeducativo - SINASE.

Embora possamos perceber que o Brasil apresenta uma política avançada em termos de rede de apoio para a infância e juventude, com uma amplitude de dispositivos que almejam assegurar os direitos desses segmentos (o Estatuto da Criança e do Adolescente, o Sistema Único de Saúde, a universalização do acesso ao ensino básico público e gratuito, entre outros), o que se constata ordinariamente na vida de crianças e jovens pobres brasileiros é uma realidade de precariedade, negligência e violência, de acordo com dados censitários e estudos especializados na área (Dell 'Aglio, Cunningham, Koller, Borges, \& Leon, 2009; IBGE, 2011; Waiselfisz, 2004, 2011).

São, portanto, enormes as lacunas e os desafios para a consolidação da Doutrina da Proteção Integral a crianças e adolescentes estabelecida pelo ECA, para a efetivação de Políticas Públicas que assegurem essa proteção e os direitos desses atores sociais, a implementação da intersetorialidade das ações e a efetivação das missões e objetivos previstos nas instituições destinadas a assegurar a prioridade definida pela Constituição (família, escola, conselhos de direito e tutelares, instituições de atendimento em geral, tanto governamentais como não governamentais).

$\mathrm{Na}$ interface entre as virtualidades e concretudes das políticas públicas destinadas aos jovens, perguntamo-nos sobre os seus efeitos práticos nas trajetórias pessoais. De que forma essas políticas, ora ausentes ora tíbias, atravessam as biografias desses jovens, condicionando suas oportunidades de desenvolvimento e bem-estar? Que alternativas encontram os jovens para contornar as ausências e óbices do apoio institucional e projetar-se para o futuro incerto? Como negociam aquilo que precisam e procuram navegar seu caminho em direção ao que lhes parece bom, desejável e justo?

\section{O desenvolvimento da pesquisa}

Durante as visitas agendadas para aplicação do questionário nas escolas públicas, membros da equipe de pesquisa solicitaram à direção e ao corpo docente da escola que indicassem estudantes que pudessem contribuir para esclarecer sobre a temática do risco e proteção juvenil, contando suas histórias. Foi destacado que os pesquisadores estavam interessados tanto em ouvir alunos que apresentavam histórico mais "difícil" em relação ao enfrentamento de adversidades no campo material, familiar, acadêmico e outros, quanto os que se mostravam mais capazes de superar problemas similares, mostrando-se bem na escola, na família e noutros contextos. Também em sala de aula, no primeiro momento do contato com os jovens para explicar a pesquisa e dar instruções, a equipe fez convites gerais, solicitando voluntários que quisessem participar da fase de entrevistas. As entrevistas foram realizadas por uma entrevistadora da equipe ou por uma dupla em salas cedidas pela direção de cada escola.

Assim, entrevistas narrativas foram realizadas com 21 jovens, utilizando de forma adaptada a técnica de Fritz Schütze (1983/2010), segundo a qual um relato autobiográfico inicial é desencadeado de forma livre, solicitando apenas que o entrevistado conte sua vida e, ao final do relato "improvisado", podem ser feitas algumas perguntas referentes à história e ao objeto de estudo em foco. Fundado na sociologia biográfica interpretativa, o objetivo dessa metodologia não é simplesmente conhecer a história de vida particular dos narradores, mas estudar as relações entre, de um lado, eventos históricos e condições socioestruturais e, de outro, as construções biográficas. Interessam particularmente em que contextos e circunstâncias as biografias foram construídas e o que move, impede e transforma as experiências e ações dos indivíduos em suas trajetórias.

$\mathrm{Na}$ fase de iniciação da entrevista narrativa, cada entrevistador apresentou a questão gerativa: "Estou pesquisando histórias de vida de jovens da cidade de Fortaleza e gostaria de conhecê-lo melhor. Para isso peço que você conte a sua história do modo que achar conveniente. Você pode levar o tempo que quiser, começar e terminar sua história como desejar, contando sua vida de modo que eu compreenda quem você é. Para que você conte sua história livremente, eu não vou interrompê-lo. Você deve me dizer quando a história acabou e somente depois 
eu farei algumas perguntas para esclarecer o que não entendi bem. Certo?" Durante a narração central, cada informante produziu um relato espontâneo sobre sua vida, com um mínimo de intervenção da entrevistadora até a indicação de finalização por parte do narrador.

Na segunda fase - a das "perguntas imanentes" (referentes ao conteúdo da história contada) - após indicação do narrador de que a história havia acabado, a entrevistadora fez, quando necessário, algumas perguntas para esclarecimentos (por exemplo, "não entendi quando você disse..."). Posteriormente, na fase das "perguntas exmanentes" (referentes ao interesse do pesquisador), cada entrevistador fez perguntas mais dirigidas à problemática do risco, vulnerabilidade e proteção juvenil: 1) Você tem algum medo na sua vida? Fale-me sobre isso. 2) Você se sente um jovem desprotegido, desamparado? Como assim? 3) Que situações você acha que mais trazem risco para você, mais prejudicam seu desenvolvimento? 4) Você acha que pode evitar esses riscos? Como você evita essas situações? 5) Você se considera forte para enfrentar as dificuldades da sua vida, mesmo que elas pareçam sem solução? Fale-me sobre situações como essas que você vivenciou. 6) Que situações você acha que mais trazem benefício para você, mais ajudam o seu desenvolvimento? 7) Quem ou o que lhe ajuda nas horas difíceis? 8) Quais são seus planos para o futuro?

Cada história contada pelos jovens é uma construção que envolve uma tessitura complexa das tensões assinaladas acima e as soluções relatadas pelos jovens não obedecem a uma lógica causal ou linear. Optamos aqui por apresentar como o campo de tensões se apresenta nas entrevistas realizadas e como certas tensões tendem a dominar a configuração da história e a avaliação autobiográfica do jovem.

\section{Percepção da rede de apoio disponível: o que contam os jovens entrevistados}

Em termos gerais, os relatos revelam a onipresença do campo de tensões referente ao acesso a recursos materiais, com as temáticas da desvantagem social em variados planos (financeiro, habitação, saúde, educação, trabalho, lazer) apresentando-se seja como pano de fundo de eventos estressores, seja como questão central a ser contornada pelos jovens em seu cotidiano e no futuro. Processos de resiliência juvenil aqui envolvem a adoção de muitos esquemas de ação visando superar as dificuldades financeiras da família em circunstâncias marcadas por baixa escolarização dos pais, desemprego ou emprego precário dos responsáveis, bem como escassez ou baixa qualidade de equipamentos públicos potencialmente capazes de minorar tais desvantagens (ex. escolas e hospitais públicos degradados). Os desafios frente à indisponibilidade de recursos materiais se apresentam em histórias que tratam, entre outros tópicos, da migração do jovem e/ou de suas famílias para a capital, do declínio financeiro em seguida ao divórcio dos pais, de trabalhos precários e mal pagos que impõem sacrifícios pessoais ao jovem, de circunstâncias desfavoráveis que se repetem entre as gerações no contexto de vida das classes populares e que o jovem sente obrigação de superar. São histórias pregressas de vulnerabilidade que atingiram pais e avós e que mobilizam o jovem a estudar mais para obter melhores ganhos no futuro e ajudar seus pais e parentes. Nesse sentido, vemos entrelaçaremse as tensões por recursos no campo material com as tensões referentes ao senso de coesão social. A jovem C.R., de 16 anos, aluna do $2^{\underline{o}}$ ano do ensino médio ilustra o compromisso que muitos jovens confessam de interromper a circularidade da pobreza na sua família, muitas vezes definida por uma sequência deletéria de fatos (ex. gravidez precoce da mãe, interrupção dos estudos dos pais, subemprego/desemprego, dependência financeira de terceiros):

Eu me sinto triste por ver que determinadas pessoas da minha família necessita (sic) de coisas importantes, que minha mãe tem um determinado sonho, tem um determinado objetivo e ele não possa ter alcançado pelo (sic) um erro que ela cometeu na adolescência (choro), aí eu tenho, meu maior objetivo é dar tudo aquilo que a minha mãe um dia quis, era, tipo, quero dar maior conforto do mundo pra (sic) ela (...) E é assim, em relação aos estudos é muito cansativo, mas é como eu tô (sic) te dizendo, eu tenho um objetivo né, que é estabilidade financeira pra (sic) eu poder auxiliar a minha família e pra (sic) eu poder fazer aquilo né, que é ajudar as outras pessoas e tal, aquilo que eu pretendo fazer, que eu quero fazer.

Não é surpreendente, portanto, que em termos de planos de futuro, 17 dos 21 entrevistados pretendam cursar o ensino superior e obter um emprego mais qualificado e quase todos vejam como imperativo finalizar o ensino médio. Os valores da educação e da formação profissional dominam os relatos revelando como os jovens, suas famílias e escolas partilham crenças e valores comuns sobre o empoderamento pessoal e coletivo por meio das instituições acadêmicas. Respondendo à pergunta sobre as "situações que mais trazem benefício ao seu desenvolvimento", o jovem refere os estudos e o ambiente escolar como importante recurso, juntamente com o apoio parental e as "boas amizades".

Eu acho que só o estudo mesmo, porque outra coisa não ajuda, mas só o estudo mesmo. Só o que dá certo nessa vida." (R.O., aluno do $7^{\underline{0}}$ ano do ensino fundamental). "Estudar sabe, você aprende muita coisa e aí pode ser alguém na vida. (M.A., 14, aluno do $8^{\underline{o}}$ ano do ensino fundamental).

Eu acho que uma coisa que seja boa pra me trazer benefícios é meus estudos porque sem ele, como eu já falei, eu não vou pra frente (...), eu penso assim, se eu não estudar, eu não vou ser uma pessoa digna da sociedade, ser uma pessoa que possa ter assim ter, assim, uma coisa sua mesmo, aí eu tento estudar muito agora mesmo eu tô tentando estudar mesmo (C.L., 18, aluna do $2^{\underline{0}}$ ano do ensino médio).

Eu agradeço pela escola que eu tenho porque é uma oportunidade única, eu me esforço o máximo possível pra tirar nota boa, eu tenho muita dificuldade em matéria, mas eu me esforço, sim corro atrás dos mais inteligentes da minha sala pra poder me ensinar (C.A., 16 anos, aluna do $2^{\circ}$ ano do ensino médio).

Se, no plano prospectivo, o binômio escola-trabalho é construído como fonte de poder pessoal e associa-se a experiências de cuidado de si e dos outros, observamos um frágil 
balanço no campo das experiencias de poder e controle quando se trata de obter hoje os recursos para concretização dos sonhos de futuro. Com efeito, a resiliência implica também a capacidade de alterar as circunstâncias que atrasam ou impedem o alcance de recursos necessários ao desenvolvimento. Entretanto, os relatos dos jovens exibem, muitas vezes em tom queixoso, sua consciência dos direitos e benefícios que thes são ordinariamente suprimidos numa sociedade desigual. São escolas, serviços de saúde, transportes públicos, condições de moradia, segurança e lazer percebidos como deficitários e fora do controle de suas ações.

C.R., aluna do $2^{\underline{O}}$ ano do ensino médio, inicia sua narrativa contando sua difícil jornada em busca de melhores oportunidades de aprendizagem no ensino público, uma vez que os recursos de sua família não permitem que ela e sua irmã frequentem simultaneamente uma escola privada:

Sincera, sinceramente, tinha professora lá que pelo amor de Deus, só a misericórdia, o ensinamento da escola pública tá altamente defasado, era contado a dedo os professores de lá que prestavam porque os professores que não prestavam era demais, era a maioria... vencia qualquer... era terrível.

Queixas sobre as ausências e deficiências dos equipamentos públicos pontilham os relatos, de forma mais ou menos contundente em todas as áreas, contribuindo para uma experiência cotidiana de desamparo na esfera pública: “Aí, assim, os hospitais públicos, eles já são altamente precários, arcaicos, o povo de hospital público é terrível, você depender de hospital público, pelo amor de Deus... (C.R., 16 anos, aluna do $2^{\underline{0}}$ ano do ensino médio).

Ó, com essa falta de ônibus, né? A gente as vezes tem que ir pra casa andando, aí quando a gente vai pra casa a gente tem que passar por esse ambiente, né? O [bairro] São Miguel. E aí? Pode vim um ... homem pegar menina pra fazer o que não presta, só o que tem aí é ladrão, se você não tem nada lhe mata, se você tem

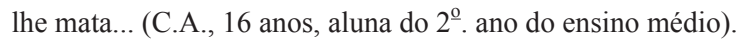

O bairro que eu moro faz fronteira com outro bairro, digamos, um pouco perigoso e às vezes pra eu chegar ao meu bairro eu tenho que passar por esse, logo há o risco de ser assaltado, perder a vida, essas coisas, os riscos iminentes, tanto pra jovens, quanto pra adultos, quanto pra crianças. (D.E., 15 anos, aluno do $2^{\underline{o}}$ ano do ensino médio).

Tais deficiências, mais dificilmente superadas, pois relativas a condições socioestruturais mais abrangentes, são contornadas pelos jovens por uma disposição voluntarista, ou melhor, uma sobrevalorização da esfera íntima, dos próprios recursos pessoais e do apoio familiar e dos pares como principal meio de enfrentamento. Nesse sentido, esses resultados ressoam outros estudos sobre juventude no Brasil que assinalam o reforço da esfera privada e a família como principal referência subjetiva. Como assinala Gonçalves (2005), "O jovem brasileiro atribui à família expectativas que nas sociedades centrais são compartilhadas por outras instâncias sociais; a retração do público reforça o privado e faz com que repousem no sujeito e no núcleo familiar as forças de agregação social” (p. 213).
Essas expectativas não se dão sem contradições evidentes, especialmente quando se revela que as famílias são elas mesmas fonte de violência, com episódios de humilhações, espancamentos do jovem, irmãos e mãe (especialmente pelo pai), abuso sexual no passado e até homicídio ou tentativa de homicídio na família.

O viés voluntarista do "querer é poder" atravessa de modo singular a relação entre as experiências do jovem em direção a uma identidade pessoal socialmente valorizada e aquelas referentes ao poder e controle. I.A., 15 anos, aluno do $9^{\underline{0}}$ ano do ensino fundamental, ilustra uma percepção comum entre os entrevistados de que o jovem corre certos riscos - como, por exemplo, vender e consumir drogas - por escolha pessoal, mas que também pode fugir deles fundamentalmente por vontade própria. Tendo ele mesmo uma história de envolvimento precoce com álcool e outras drogas e liderado por certo período o tráfico em seu bairro (em sucessão ao seu irmão mais velho), refere motivações de foro íntimo para esses comportamentos: uma depressão causada pelo falecimento do pai e certa fraqueza da vontade ou imaturidade para resistir às "falsas amizades" e enfrentar os conflitos no espaço doméstico:

Eu vivia com o meu pai, era muito apegado ao meu pai, sempre vivia grudado com ele, sempre. Aí quando eu tinha onze ele morreu do coração. Ai eu fiquei com depressão, passei dois anos com depressão. Ai quando eu cheguei nos treze anos eu saí. Aí eu parti pro álcool e pras drogas. Do álcool, eu bebia socialmente e tal. Ai eu comecei a me envolver com esse pessoal. (...) Drogas era como um remédio pra mim. Eu cheirava... era só cocaína, era só pó. Eu usava, aí eu me sentia melhor, né? Era como um remédio, eu usava e se sentia melhor. E se saía daquela solidão. (...) Aí, isso eu me envolvi mais ainda: "Não, ele é teu irmão, tu vai ser o sucessor dele". Aí, com isso, a cabeça, moleque, botaram na minha cabeça, aí eu pô. Eu ficava alegre, animado, conversava com todo mundo (...) Aí tudo, tudo, eu tinha tudo do bom e do melhor, escola particular, tudo, tudo. Até que eu parei, parei pra pensar, né? Veio me dando conselho, minha irmã também. Aí eu parei pra pensar. Cara eu... isso não vale a pena não, isso é bom no momento. Rapaz, meu futuro não vai ser muito legal. Aí eu me decidi a se afastar disso. Aí com 14 anos decidi me afastar. Eu já estava alucinado, sem ter amizade, amizade, a amizade que eu tinha era amizade falsa, ali que tavam querendo se aproveitar de mim. Aí, tudo bem, eu passei, parei um pouco, pensei na vida. Aí continuei estudando, aí só que isso eu voltei. Teve festa, eu voltei, eu não me controlava. Voltei, voltei, fiz minha mãe chorar (...) Aí com isso a minha mãe foi se chateando, aí falava: "eu vou mandar tu embora daqui" tal tal. Aí dois, três meses depois (...) em janeiro, ela botou pra eu vim pra cá. Aí com isso eu parei, parei de fazer isso. Sem vontade de voltar mais. Eu parei totalmente de fazer essas coisas. Aí hoje eu vivo aqui, aqui na escola há 3 meses. (...) é isso ai. Aí eu parei, até hoje eu tô vivendo muito bem. Aí, em julho eu vou pra lá pra ver se eu me controlo. Aí essa é a história da minha vida. Eu espero me distanciar das amizades que me influenciam, né? Que a gente vai mais pelas amizades. A gente não faz... a gente só faz o que quer, mas as amizades influenciam muito. Porque a gente tá lá, né? A gente vê eles 
fazendo, a gente sente vontade também de fazer.

Perguntados se se sentiam "desprotegidos, desamparados", catorze jovens entre os vinte e um entrevistados responderam negativamente, principalmente porque pais, familiares amigos e namorados, mas também outros adultos como alguns professores e mentores da igreja, forneciam o apoio necessário. Nas horas difíceis, essas pessoas aparecem como a principal fonte de suporte social, reforçada às vezes pela menção a Deus e à religião. Religiosidade e espiritualidade têm sido compreendidas nos estudos sobre risco social como fatores de proteção no nível individual ou indicadores de "positividade pessoal" que atuam articulados com fatores de apoio em nível social (Amparo et al, 2008; Koller, Ribeiro, Cerqueira-Santos, Morais, \& Teodoro, 2005; Libório, 2007). Aqui, o recurso a Deus, destacado em cerca de um terço das entrevistas, contribui para a auto-percepção do jovem como alguém rumo a uma identidade pessoal desejável e que, em último caso, na ausência ou negligência de seus familiares e amigos, ainda dispõe de um porto-seguro. De modo geral, os jovens percebem-se fortalecidos principalmente no campo das relações interpessoais mais próximas, isto é, os outros significativos com os quais de fato podem contar no dia a dia. Daí que, indagados sobre os seus medos, mais da metade dos entrevistados refere-se aos relacionamentos de apoio, isto é, à possibilidade de perder definitivamente relações que fornecem suporte emocional e proteção, como é o caso de morte dos pais, avós e amigos queridos.

No aspecto referente às experiências de justiça social, as narrativas dos jovens transparecem um conjunto de temáticas que oscila entre os problemas macrossociais vinculados à condição de classe e pobreza e variadas circunstâncias em que são vitimados por relações desiguais ou violentas nos espaços domésticos e na comunidade. Dignos de nota são os efeitos em cascata da violência contra a mulher, que prejudicam o jovem, mas também sua família como um todo, bem como sua comunidade. São agressões (muitas vezes efetuadas por maridos alcoolizados) que geram fugas das mães e seus filhos para outras cidades, separações, declínio financeiro, trabalho precário, condições de vida inferiores, adoecimento e, acima de tudo, processos de sofrimento que podem se prolongar, afetando a saúde física e mental do jovem. As situações de preconceito também devem ser contornadas em formas de resistência e solidariedade que podem resultar em empoderamento e fortalecer o senso de justiça social entre os jovens. Como ilustra a história de E.M., 19 anos, estudante do $2^{\underline{o}}$ ano do ensino médio, que desafiou expectativas culturais ao optar pela transexualidade, reivindicando seu direito à diferença com a ajuda de amigos e, mais tarde, da própria família:

Aí, aos 16, eu me decidi, minha vida a partir daí, o que eu queria ser, e foi assim meio difícil, porque a minha mãe, a minha família, às vezes, não aceitava. Eu sofri, sofri muito, mas aí, ao passar o tempo, a minha família começou a aceitar do jeito que eu sou, do jeito que eu sou agora. Hoje, eu dou graças a Deus que eu tenho a minha família, que ela me aceita do jeito que eu sou, eu não tenho mais aquela angústia que eu tinha (...). Nessa parte aí eu sou a pessoa mais feliz do mundo de eu ter descoberto o que eu queria, ser uma pessoa aceita, minha alegria é ser uma pessoa aceita e não ter mais aquela angústia que eu sempre tinha.

Como no caso de EM, as biografias dos jovens entrevistados envolvem abrir caminho ao desenvolvimento psicossocial enfrentando normas e valores culturais que podem ser opressivos no plano das relações de gênero, da orientação sexual e outros. Assim, os jovens devem navegar entre os dilemas da aderência cultural e os da justiça social.

\section{Considerações finais}

À luz de uma concepção de resiliência como processo dinâmico e interdependente entre o indivíduo e suas ecologias materiais e sociais, este trabalho discutiu como as narrativas autobiográficas de jovens em desvantagem socioeconômica são atravessadas por um tecido de "tensões" que condicionam sua auto-percepção como protegidos ou desprotegidos. Ao evitar a ênfase sobre as capacidades pessoais de enfrentamento e conceber a resiliência também em termos do que as comunidades podem fornecer ao jovem como suporte rumo ao pleno desenvolvimento psicossocial, com saúde e bem-estar, essa concepção contribui para desvelar o conjunto de problemas enfrentados pelos jovens para conduzir suas vidas, especialmente quando lhes estorvam ou negam essa rede de apoio comunitário. Nesse sentido, as histórias contadas pelos entrevistados trazem evidências do impacto biográfico da ausência articulada das políticas públicas no campo educacional, laboral, de segurança, de saúde, bem como aquelas destinadas mais diretamente às juventudes. Ora mais ora menos conscientes dessa ausência, os jovens em desvantagem socioeconômica ressentem-se da não efetivação do sistema de apoio macrossocial em rede, o que pode motivá-los a buscar recursos protetivos onde esses estão mais acessíveis, isto é, na esfera privada. Os recursos mais acessíveis são a própria interioridade (personalidade, disposições pessoais, força de vontade, reflexividade, espiritualidade) e as relações interpessoais no espaço familiar e entre amigos. No plano microssocial da rede, algumas pessoas em particular figuram como tutores ou adjuvantes, desempenhando papel significativo no suporte emocional dos jovens, especialmente em momentos mais difíceis. São mães, amigos íntimos, religiosos e professores isolados que atuam ouvindo e aconselhando o jovem ou servindo de modelo de vida, sendo reconhecidos e valorizados como pessoas especiais na sua formação.

Reveladora dos impedimentos do jovem na obtenção dos recursos necessários ao seu desenvolvimento é a contradição entre a escola como instituição, percebida como de baixa qualidade e a educação como recurso para superação das condições precárias de vida. Contrastando com a partilha praticamente unânime no valor da escolarização como meio de ascensão social, os jovens entrevistados percebem a inferioridade da escola pública que lhes é oferecida, muitas vezes mencionando a sua diferença em relação à escola particular. Ainda assim, esse espaço escolar degradado é fonte importante de apoio enquanto locus de relações interpessoais significativas (especialmente de amigos íntimos) que ajudam a enfrentar os episódios e situações de sofrimento e a sustentar projetos de vida. 
Finalmente, algumas notas sobre a nossa opção metodológica. Como afirma Ungar (2003), estudar a problemática da resiliência por meio de um desenho qualitativo de pesquisa permite contornar alguns obstáculos impostos pela pesquisa quantitativa que levanta fatores de proteção e de "risco" social. O primeiro é a arbitrariedade na seleção de variáveis de "resultado" da resiliência, que implica, por exemplo, na dificuldade de definir um "bom" desfecho do desenvolvimento psicossocial. O outro é o desafio de explicar o contexto sociocultural no qual a resiliência ocorre e que se mostra bastante heterogêneo e situado nos estudos transculturais. A adoção do modelo da resiliência como "navegação em direção a" e "negociação de" recursos propõe solucionar esses impasses e resulta de estudos que se valeram de entrevistas e observações participantes, como complemento a estudos estatísticos. Para o autor, entre as vantagens do desenho qualitativo estão: sua adequação para a descoberta/construção de novos processos de proteção relevantes na experiência vivida dos participantes da pesquisa; o fato de fornecer uma "descrição densa" dos fenômenos em contextos bem específicos; a possibilidade de fortalecer vozes minoritárias a definirem, em seus próprios termos, o que vem a ser positivo para o seu desenvolvimento; e a exigência de que o pesquisador reflita sobre possíveis vieses de base. Em nosso estudo, mais particularmente, vislumbramos que o emprego de entrevistas narrativas autobiográficas com os jovens pode abrir um espaço adicional de apoio pela possibilidade de estimular a reflexão e o ordenamento das próprias vivências dos participantes - o que Schütze chama de "trabalho biográfico". A entrevista narrativa funciona como momento dialógico em que, na presença de um pesquisador interessado e comprometido, o jovem pode concatenar narrativamente suas experiências, avaliando passado e presente rumo ao futuro que se descortina.

\section{Referências}

Amparo, D. M., Galvão, A. C. T., Alves, P. B., Brasil, K. T., \& Koller, S. H. (2008). Adolescentes e jovens em situação de risco social: redes de apoio social e fatores pessoais de proteção. Estudos de Psicologia, 13(2), 165-174.

Andrade, G. R. B., \& Vaitsman, J. (2002). Apoio social e redes: conectando solidariedade e saúde. Ciência \& Saúde Coletiva, 7(4), 925-934.

Costa, L. G. (2009). A rede de apoio social de jovens em situação de vulnerabilidade social e uso de drogas (Dissertação de Mestrado). Recuperado de http://hdl.handle.net/10183/16339 (000699006)

Estatuto da Criança e do Adolescente. Lei Federal no 8069 (1990). Brasília: Congresso Nacional. Recuperado de http://www.planalto.gov.br/CCIVIL/ LEIS/L8069.htm
Dell Aglio, D. D., Cunningham, Koller, S. H., Borges, V. C., \& Leon, J. S. (2009). Índice de Bem-Estar Infanto-Juvenil: um levantamento de indicadores sociais. In R. M. C. Libório \& S. H. Koller (Orgs.), Adolescência e juventude: risco e proteção na realidade brasileira (pp. 57-78). São Paulo: Casa do Psicólogo.

Dell’Aglio, D. D., Kolller, S. H., \& Yunes, M. A. M. (Orgs). (2006). Resiliência e Psicologia Positiva: interfaces do risco à proteção. São Paulo: Casa do Psicólogo.

Gonçalves, H. S. (2005). Juventude brasileira, entre a tradição e a modernidade. Tempo Social (Revista de Sociologia da USP), 17(2), 207-219.

IBGE. (2011). Censo 2010. Recuperado de http://www.censo2010.ibge.gov.br/ sinopse/.

Koller, S.H., Ribeiro, J., Cerqueira-Santos, E., Morais, N. A., \& Teodoro, M. L. (2005). Juventude Brasileira: Comportamento de risco, fatores de risco e de proteção (Relatório Técnico/2005). Washington, DC: Banco Mundial.

Libório, R. M. C. (2007). Comportamentos e fatores de risco e proteção na adolescência e juventude nos municipios de Presidente Prudente e Belo Horizonte (Relatório de pesquisa/2007), Presidente Prudente, SP, Faculdade de Ciências e Tecnologia, Universidade Estadual Paulista (UNESP).

Libório, R. M. C. (2009). Escola: risco, proteção e processos de resiliência durante a adolescência. In Associação Nacional de Pesquisa em Educação (ANPED) (Org.), Anais eletrônicos da reunião anual da Associação Nacional de Pesquisa em Educação (ANPED), Caxambu, MG, Brasil, 32. Recuperado de http://www.anped.org.br/reunioes/32ra/arquivos/trabalhos/GT20-5283--Int.pdf

Libório, R. M. C, \& Ungar, M. (2010). Hidden resilience: the social construction of the Concept and its implications for professional practices with at-risk adolescents. Psicologia: Reflexão e Crítica, 23(3), 476-484.

Marques, E., \& Bichir, R. (2011). Redes de apoio social no Rio de Janeiro e em São Paulo. Novos Estudos - CEBRAP, 90, 65-83.

Schütze, F. (2010). Pesquisa biográfica e entrevista narrativa (D. Werle, Trad.). In W. Weller \& N. Pfaff (Orgs.), Metodologias da pesquisa qualitativa em Educação: teoria e prática. Petrópolis, R.J.: Vozes. (obra original publicada em 1983).

Siqueira, A. C., Betts, M. K., \& Dell Aglio, D. D. (2006). A rede de apoio social e afetivo de adolescentes institucionalizados no sul do Brasil. Revista Interamericana de Psicologia, 2(40), 149-158.

Ungar, M. (2003). Qualitative contributions to resilience research. Qualitative social work, 2(1), 85-102.

Ungar, M. (2004). A constructionist discourse on resilience: multiple contexts, multiple realities among at-risk youth. Youth Society, 35, 341-365.

Ungar, M., Brown, M., Liebenberg, L., Cheung, M., \& Levine, K. (2008). Distinguishing differences in pathways to resilience among Canadian youth. Canadian journal of community mental health, 27(1), 1-13.

Waiselfisz, J. J. (2004). Relatório de Desenvolvimento Juvenil 2003. Brasília: UNESCO.

Waiselfisz, J. J. (2011). Mapa da violência 2011: os jovens do Brasil. São Paulo: Instituto Sangari.

Yunes, M. A. M. (2003). Psicologia positiva e resiliência: o foco no indivíduo e na família. Psicologia em Estudo (Maringá), 8(Num. Esp.), 75-84.

Idilva Maria Pires Germano, doutora em Sociologia pela Universidade Federal do Ceará, é professora associada da Universidade Federal do Ceará (UFC). Endereço para correspondência: Universidade Federal do Ceará, Centro de Humanidades, Departamento de Psicologia, Av. da Universidade 2762, Benfica, Fortaleza, CE. CEP 60020-180. Telefone: (85) 33667661. E-mail: idilvapg@ufc.br

Veriana de Fátima Rodrigues Colaço, doutora em Educação pela Universidade Federal do Rio Grande do Sul, é professora associada da Universidade Federal do Ceará (UFC). E-mail: verianac@uol.com.br 